\title{
REVIEW
}

\section{Foster $^{\circledR}:$ A High-Efficiency Combination Metered Dose Inhaler with Consistent Particle Size Distribution at Alternative Flow Rates}

\author{
Roberta De Maria • Ingrid Zagnoni • Alessandro Bodria • \\ Sauro Bonelli • Massimiliano Dagli Alberi • David Andrew Lewis • \\ Rob Johnson · Helen O'Shea
}

To view enhanced content go to www.combitherapy-open.com Received: November 8, 2013 / Published online: January 3, 2014

(C) The Author(s) 2013. This article is published with open access at Springerlink.com

\section{ABSTRACT}

Introduction: This publication adds perspective to a recent publication by Johal et al. that presented the performance of combination inhalation therapies at a flow rate differing from that recommended by the regulatory authorities for metered dose inhaler (MDI) performance testing. Altering the flow rate through an impactor can create potential pitfalls which can result in performance misrepresentation.

Performance Testing of MDIs at Non-Standard Flow Rates: In-house data for Foster ${ }^{\circledR}$ (Chiesi, Parma, Italy) and Flutiform ${ }^{\circledR}$ (Bard Pharmaceuticals Limited, Cambridge, UK) have been collected using standard pharmacopaeial conditions and also at the unconventional $60 \mathrm{~L} / \mathrm{min}$ flow rate utilized by Johal et al.

Electronic supplementary material The online version of this article (doi:10.1007/s13556-013-0006-6) contains supplementary material, which is available to authorized users.

R. De Maria - I. Zagnoni - A. Bodria - S. Bonelli ·

M. D. Alberi

Chiesi Farmaceutici SpA, Parma, Italy

D. A. Lewis $(\bowtie) \cdot$ R. Johnson · H. O'Shea Chiesi Ltd, Chippenham, Wiltshire, UK e-mail: D.Lewis@chiesi.com
A marked reduction in mass median aerodynamic diameters (MMADs) of both the inhaled corticosteroids (ICS) and long-acting beta agonists in Foster MDI from approximately $1.2-0.5 \mu \mathrm{m}$ with increase in flow rate (Johal et al.) is not observed. Use of the Andersen cascade impactor at flow rates above $28.3 \mathrm{~L} / \mathrm{min}$ is not common practice. The industry generally utilizes data from the next generation impactor (NGI), an impactor specifically designed and developed for this purpose. Data for the ICS component of Foster have been generated using an NGI operated at 30 and $60 \mathrm{~L} / \mathrm{min}$, yielding an MMAD $( \pm S D)$ of $1.1 \pm 0.1 \mu \mathrm{m}$ at both flow rates.

Therapeutic Significance of Submicron Particles: Johal et al. suggest that submicron particles are prone to be exhaled by the patient, and therefore imply that they may be noneffective. However, therapeutic significance of submicron particles is supported by a scintigraphic lung deposition study carried out using the Foster MDI. The in vivo data highlight that just $2-3 \%$ of the nominal dose was exhaled, with $31-34 \%$ deposited in the lungs.

Conclusion: Consistent particle size distribution of both active drug components 
delivered from Foster MDI at flow rates of 28-30 and $60 \mathrm{~L} / \mathrm{min}$ is observed.

Keywords: Metered dose inhaler; Particle size distribution; Andersen cascade impactor; Next generation impactor; Sampling flow rate; Foster; Flutiform

\section{INTRODUCTION}

Characterization of the performance of metered dose inhalers (MDIs) by cascade impaction is a complex procedure, requiring the pertinent selection of many experimental and environmental variables in order to achieve realistic and relevant results. Examples have been published illustrating that MDI delivery performance variability may occur under extreme ambient conditions [1-3].

No less crucial is appropriate analysis of the resulting data in order to calculate accurate values for performance indicators such as mass median aerodynamic diameter (MMAD) and fine particle dose (FPD) [4]. Industry approved software is available to facilitate the appropriate processing of experimental data in accordance with regulatory guidelines (CITDAS V3.10, Copley Scientific, Nottingham, UK).

This publication adds perspective to a recent publication by Johal et al. [5] that presented performance of combination inhalation therapies at a flow rate, $60 \mathrm{~L} / \mathrm{min}$., differing from that recommended by regulatory authorities for Metered Dose Inhaler performance testing, $28.3 \mathrm{~L} / \mathrm{min}$ [United States Pharmacopeia (USP) 36]. Altering the flow rate through an impactor can create potential pitfalls, including impactor choice and preparation (i.e., plate coating) and data processing parameters, which can result in performance misrepresentation [2-4, 6-9].
This review article does not contain any studies with human or animal subjects performed by any of the authors.

\section{PERFORMANCE TESTING OF MDIS AT NON-STANDARD FLOW RATES}

Johal et al. [5] utilized a dosing procedure that, seemingly, is non-compliant with the patient instruction leaflet [10]. Furthermore, it is known that a combination of low dose number and uncoated impactor plates results in the underestimation of particle size information $[2,3,6,7]$. In addition, figure two of the Johal et al. [5] paper utilizes identical impactor stage cut-off diameters for the Andersen Cascade Impactor (ACI), at both 28.3 and $60 \mathrm{~L} / \mathrm{min}$ sampling flow rates, rather than calculating precise stage cut-off diameters and appropriately representing the data $[8,9]$. Table 1 presents our in-house data for Foster ${ }^{\circledR}$ (Beclometasone dipropionate and Formoterol Fumarate, Chiesi, Parma, Italy) and Flutiform ${ }^{\circledR}$ (Fluticasone propionate and Formoterol Fumarate, Bard Pharmaceuticals Limited, Cambridge, UK) collected using standard pharmacopaeial conditions and also at the unconventional $60 \mathrm{~L} / \mathrm{min}$ flow rate utilized by Johal et al. [5]. The data in Table 1 have been processed with ACI stage cut-off diameters in accordance with Van Oort et al. [9]. A marked reduction in MMADs of both the inhaled corticosteroids (ICS) and long-acting beta agonists (LABA) in Foster MDI from approximately $1.2-0.5 \mu \mathrm{m}$ with increase in flow rate (Johal et al. [5]), which permits a potential misrepresentation of the product's characteristics, is not observed. Furthermore, careful inspection of the cumulative fractional frequency-LABA particle size distribution curves presented in figure $2 d$ of their paper [5], 
Table 1 MMAD values $(n \geq 6)$ for Foster and Flutiform delivered to ACI at alternative flow rates

\begin{tabular}{|c|c|c|}
\hline \multirow[t]{2}{*}{ Product } & \multicolumn{2}{|c|}{$\operatorname{MMAD}(\mu \mathrm{m}) \pm$ standard deviation } \\
\hline & $28.3 \mathrm{~L} / \mathrm{min}$ & $60.0 \mathrm{~L} / \mathrm{min}$ \\
\hline \multicolumn{3}{|l|}{ Foster } \\
\hline $\mathrm{BDP}$ & $1.3 \pm 0.1$ & $1.2 \pm 0.2$ \\
\hline FF & $1.4 \pm 0.2$ & $1.2 \pm 0.2$ \\
\hline \multicolumn{3}{|c|}{ Flutiform } \\
\hline FP & $4.0 \pm 0.1$ & $3.6 \pm 0.1$ \\
\hline $\mathrm{FF}$ & $3.6 \pm 0.1$ & $3.2 \pm 0.2$ \\
\hline
\end{tabular}

$A C I$ Andersen cascade impactor, $B D P$ beclometasone dipropionate, $F F$ formoterol fumarate, $F P$ fluticasone propionate, $M M A D$ mass median aerodynamic diameter

would suggest that MMADs derived from these plots are consistent with those shown in Table 1. The Geometric Standard Deviation observed for the $60 \mathrm{~L} / \mathrm{min}$ Foster in-house data was 1.8 , well below the surprising high value of 5.3 reported by Johal et al. [5].

Use of the ACI at flow rates above $28.3 \mathrm{~L} / \mathrm{min}$ is not common practice $[8,9]$. The industry generally utilizes data from the next generation impactor (NGI; USP 36, Apparatus 6), an impactor specifically designed and developed for this purpose [11]. In-house data for the ICS component of Foster have been generated using an NGI operated at 30 and $60 \mathrm{~L} / \mathrm{min}$ yielding an MMAD $( \pm S D)$ of $1.1 \pm 0.1 \mu \mathrm{m}$ at both flow rates. The equivalence of the particle size distributions for the ICS and LABA components emitted from Foster has previously been published [12].

Johal et al. [5] report all fine particle drug delivery data normalized to nominal label claim rather than using the accepted pharmacopoeial approach of calculation against drug mass (dose), delivered to the ACI, ex-actuator, nor is it confirmed that drug mass balance against experimental delivered dose uniformity was achieved (USP 36), which is unhelpful. Furthermore, reporting that Flutiform has a higher and more consistent fine particle fraction (FPF) than Foster is potentially misleading, firstly, because the ICS components are chemically and physically different and formulated at different concentrations, and secondly, our in-house data generated by NGI at $30 \mathrm{~L} / \mathrm{min}$ show the converse as follows: Flutiform (FP as particulate suspension) $-\mathrm{FPD}=39 \pm 4 \mu \mathrm{g}$, FPF (as fraction of delivered dose) $37 \pm 4 \%$; Foster (BDP as solution) $-F P D=34 \pm 2 \mu$ g, FPF $40 \pm 2 \%$. The corresponding NGI data obtained at $60 \mathrm{~L} / \mathrm{min}$ are Flutiform: $\mathrm{FPD}=39 \pm 3 \mu \mathrm{g}, \mathrm{FPF}=34 \pm 1 \%$; Foster; FPD $=47 \pm 2 \mu \mathrm{g}, \mathrm{FPF}=54 \pm 2 \%$.

\section{THERAPEUTIC SIGNIFICANCE OF SUBMICRON PARTICLES}

Johal et al. [5] suggest that submicron particles are prone to be exhaled by the patient, and therefore imply that they may be non-effective. However, studies exist which contradict such a claim [13-16]. Extra-fine particles have been demonstrated to show high central and peripheral deposition within the lung, as particle diffusion processes become more dominant when particle size decreases [15]. Therapeutic significance of submicron particles is supported by a scintigraphic lung deposition study carried out using the Foster MDI [13]. The in vivo data highlight that just $2-3 \%$ of the nominal dose was exhaled, with $31-34 \%$ deposited in the lungs.

The testing of MDIs at alternative flow rates is not a common practice in the pharmaceutical industry: the majority of patient instruction leaflets, including those for Foster [10] and Flutiform [17], advocate a long, slow breath when a dose is administered; for example: "breathe in slowly and deeply"; "hold your breath for as long as possible". The patient is also directed not to perform the process "too quickly". 


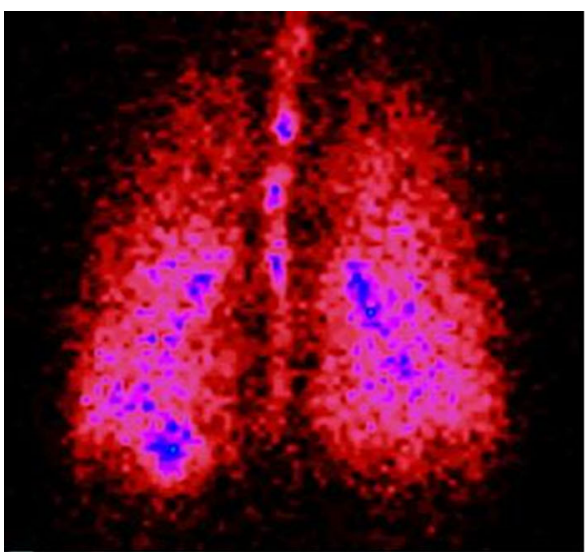

Healthy subject

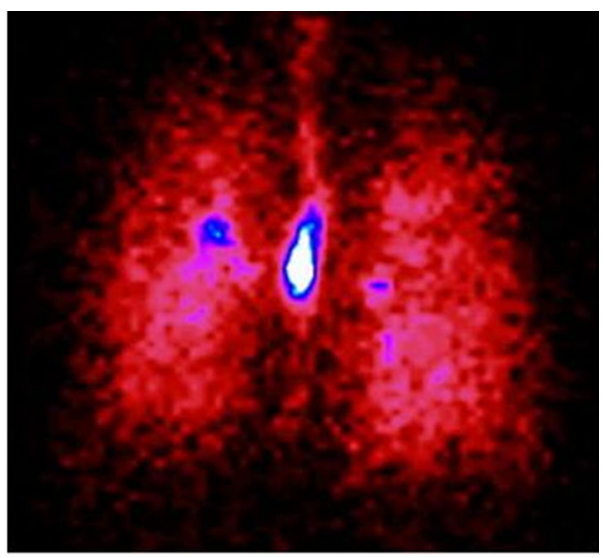

Asthma patient

Fig. 1 Scintigraphic image of healthy subject and asthma patient after a single inhalation of four puffs of Foster (BDP/FF; 100/6), metered dose inhaler. $B D P$ beclometasone dipropionate, $F F$ formoterol fumarate

Figure 1 demonstrates that for subjects with alternative breath capabilities, similar drug deposition is obtained, highlighting the robustness of Foster MDI drug in vivo delivery performance for both healthy and injured lungs. Analysis of 8 patients with asthma and 8 healthy subjects showed a lung deposition of $30.9 \pm 8.9$ and $34.1 \pm 9.3 \%$ of the nominal dose, respectively [13]. This in vivo lung deposition correlates well with published in vitro data of $35 \pm 1 \%$ of nominal dose [12].

\section{CONCLUSION}

Consistent particle size distribution of both active drug components delivered from Foster MDI at flow rates of $28-30$ and $60 \mathrm{~L} / \mathrm{min}$ is observed.

\section{ACKNOWLEDGMENTS}

D.A. Lewis is the guarantor for this article, and takes responsibility for the integrity of the work as a whole. No funding or sponsorship was received for this study or publication of this article.
Conflict of interest. R. De Maria is an employee of Chiesi Farmaceutici SpA, Parma, Italy. I. Zagnoni is an employee of Chiesi Farmaceutici SpA, Parma, Italy. A. Bodria is an employee of Chiesi Farmaceutici SpA, Parma, Italy. S. Bonelli is an employee of Chiesi Farmaceutici SpA, Parma, Italy. M. Dagli Alberi is an employee of Chiesi Farmaceutici SpA, Parma, Italy. D.A. Lewis is an employee of Chiesi Ltd, Chippenham, Wiltshire, UK. R. Johnson is an employee of Chiesi Ltd, Chippenham, Wiltshire, UK. H. O'Shea is an employee of Chiesi Ltd, Chippenham, Wiltshire, UK.

Compliance with ethics guidelines. This review article does not contain any studies with human or animal subjects performed by any of the authors.

Open Access. This article is distributed under the terms of the Creative Commons Attribution Noncommercial License which permits any noncommercial use, distribution, and reproduction in any medium, provided the original author(s) and the source are credited. 


\section{REFERENCES}

1. Shemirani FM, Hoe S, Lewis D, Church T, Vehring $\mathrm{R}$, Finlay WH. In vitro investigation of the effect of ambient humidity on regional delivered dose with solution and suspension MDIs'. J Aerosol Med Pulm Drug Del. 2012;26:1-8.

2. O'Shea H, Lewis DA. Rapid method for coating the andersen cascade impactor. In: Proceedings of drug delivery to the lungs 2011. December 7-9, 2011. pp 73-76.

3. Nasr MM, Ross DL, Miller NC. Effect of drug load and plate coating on the particle size distribution of a commercial albuterol metered dose inhaler (MDI) determined using the Andersen and Marple-Miller cascade impactors. Pharm Res. 1997;14:1437-43.

4. Lewis D, Copley M. Inhaled product characterization: calculating particle-size distribution metrics. Pharm Technol. 2011;S33-S37.

5. Johal B, Howald M, Fischer M, Marshall J, Venthoye G. Fine particle profile of fluticasone propionate/ formoterol fumarate versus other combination products: the DIFFUSE study. Comb Prod Ther. 2013;3. doi:10.1007/s13556-013-0003-9.

6. Miller NC, Ross DL, Nasr MM. Effect of formulation factors on the observed bounce in cascade impactors used to measure the spray particle size of metered dose inhalers. Int J Pharm. 1998;173:93-102.

7. Dunbar C, Kataya A, Tiangbe T. Reducing bounce effects in the Andersen cascade impactor. Int J Pharm. 2005;301:25-32.

8. Nichols SC. Andersen cascade impactor, calibration and mensuration issues for the standard and modified impactor. Pharmeuropa. 2000;12:584-8.
9. Van Oort M, Downey B, Roberts W. Verification of operating the Andersen cascade impactor at different flow rates. Pharm Forum. 1996;22:2211-5.

10. Foster (United Kingdom Trade Name: Fostair) patient instruction leaflet. 2013. http://xpil. medicines.org.uk/ViewPil.aspx?DocID=21474. Accessed 12 Dec 2013.

11. Marple VA, Roberts DL, Romay FJ, et al. Next generation pharmaceutical impactor (a new impactor for pharmaceutical inhaler testing). Part I: design. J Aerosol Med. 2003;16:283-99.

12. Lewis DA, Brambilla G, Church TK, Meakin BJ. BDP and Formoterol association within a combination HFA solution MDI. Proc Respir Drug Deliv. 2006;3:939-41.

13. De Backer W, Devolder A, Poli G, et al. Lung deposition of BDP/Formoterol HFA pMDI ion healthy volunteers, asthmatic, and COPD patients. J Aerosol Med. 2010;23:137-48.

14. Church TK, Brambilla G, Lewis DA, Meakin BJ, Poli G. Sub-micron particles: an effective means of achieving bronchodilation. Proc Respir Drug Deliv. 2010;2:509-12.

15. Brown J, Zeman K, Bennet W. Ultrafine particle deposition in the healthy and obstructed lung. Am J Crit Care Med. 2002;166:1240-7.

16. Acerbi D, Brambilla G, Lewis D, Meakin B. Gaining approval to market therapeutically equivalent inhalers in the EU: an industry perspective. Proc Respir Drug Deliv Eur. 2007;1:127-40.

17. Flutiform patient instruction leaflet. 2013. http:// xpil.medicines.org.uk/ViewPil.aspx?DocID=26957. Accessed 12 Dec 2013. 